\title{
PAISAGEM RECRIADA PROJETO DE DESCARACTERIZAÇÃO DAS BARRAGENS DA MINA DA CACHOEIRA
}

\author{
Autores: \\ AKINAGA, Patrícia. Arquiteta paisagista, Patricia Akinaga Arquitetura e Desenho Urbano \\ S/S Ltda, São Paulo-SP, Brasil Email: patricia@patriciaakinaga.com.br \\ NAMBA, Makoto. Engenheiro geotécnico, Bureau de Projetos e Consultoria, São Paulo- \\ SP, Brasil. Email: makoto@bureauprojetos.com.br \\ CUNHA, Ilton. Engenheiro de meio ambiente, Vale Manganês, Conselheiro Lafaiete-MG, \\ Brasil Email: Ilton.cunha@rdmbr.com \\ VINUEZA, German. Geólogo, Vale, Belo Horizonte-MG, Brasil \\ Email: gerrman.vinueza@vale.com \\ FONTES, Gustavo Lopes. Gerente do Morro da Mina, Vale Manganês, Conselheiro \\ Lafaiete-MG, Brasil \\ NEGRO JR, Arsênio. Diretor, Bureau de Projetos e Consultoria, São Paulo-SP, Brasil \\ Email: bureau@bureauprojetos.com.br
}

\begin{abstract}
This article discusses the decommissioning design of three tailing dams of a deactivated manganese mine located in Southern Minas Gerais State, Brazil. The landscape design recreated a natural setting characterized by constructed wetlands and vegetation, a successful alternate to the initial solution of concrete spillways. The intervention was required by the local environmental agency for overflow safety and erosion control.

The design was guided by geotechnical, geological, hydrological and biological principles.
\end{abstract}

\section{RESUMO}

O objeto do artigo é a infraestrutura verde, solução adotada para a descaracterização de três barragens de rejeito inerte da Mina de Manganês Cachoeira pertencente à Vale. A mina localiza-se no município de Ritápolis, cerca de 30 km de São João Del Rei.

O artigo examina o projeto paisagístico desenvolvido como parte do processo de desativação da mina, segundo diretrizes do órgão ambiental, em relação à segurança das barragens e a recuperação da paisagem. O objetivo do projeto não foi reproduzir a natureza que ali existiu e sim recriá-la a partir da reconciliação entre a paisagem natural e a paisagem construída dominante. Apresenta a concepção e a implementação dos alagados construídos, wetlands, e do projeto de plantio implantado. Analisa a vazão da água, o ciclo dos nutrientes, a vegetação macrófita e a insolação como elementos determinantes para o equilíbrio e para a biodiversidade. Discorre sobre a configuração atual da paisagem da área dos reservatórios , resultado da atividade de mineração: barragens de rejeito, taludes e a vegetação existente.

Como método, foi realizado levantamento de campo com a análise da fauna, flora e topografia local. Além das plantas, cortes e as elevações, foram elaboradas perspectivas e maquetes do terreno a partir das barragens existentes, lagoas e taludes suaves propostos.

A existência de nascentes à montante das barragens possibilitou o projeto. As barragens foram "desmontadas" paisagisticamente e foram substituídas por áreas alagadas, wetlands, que deram outra dinâmica ao sítio e restabeleceram conexões com a mata 
circundante. O projeto de infraestrutura verde trabalhou com a "engenharia" do terreno. As nascentes foram tomadas como elementos alimentadores do sistema além do aproveitamento das águas pluviais captadas pelas linhas de drenagem natural das áreas adjacentes.

As intervenções propostas na paisagem foram concebidas segundo princípios que levaram em conta: as compatibilidades ecológicas das espécies, a integração com a paisagem, a especificação de vegetação de menor manutenção e conforme diretrizes do biólogo da equipe quanto á sua adaptabilidade ao local ou já presentes na área de intervenção e devidamente identificadas durante o trabalho de campo.

Em conclusão, o artigo apresenta os resultados da descaracterização das barragens e a substituição por taludes galgáveis suaves. O escalonamento existente deu lugar às lagoas e áreas inundáveis constituídas por vegetação pertencente ao novo ambiente. Os diversos portes e características distintas das espécies foram elementos que enriqueceram a paisagem e sua dinâmica ecológica.

Palavras-chave: alagados construídos, desativação de mina, recuperação ambiental, paisagem recriada, infraestrutura verde.

\section{INTRODUÇÃO}

O objeto deste artigo são três barragens de rejeito resultantes da atividade de mineração de manganês na Mina da Cachoeira. A propriedade pertence a Rio Doce Manganês, do Grupo Vale e localiza-se no município de Ritápolis, cerca de 30 km de São João Del Rei, sul de Minas Gerais.

O projeto paisagístico foi realizado em conjunto com a empresa Bureau de Projetos que foi inicialmente contratada para atender o Termo de Ajuste de Conduta (TAC) resultante de uma insurgência em uma das barragens e ao mesmo tempo fazer parte do processo de descomissionamento da Mina junto ao órgão ambiental.

Estudos iniciais mostraram que não havia nenhum problema de segurança, entretanto, medidas deveriam ser tomadas para a garantia total dentro de um período de retorno maior.

O objetivo principal, ao substituir a solução tradicional de vertedouros de concreto, foi de criar um sistema seguro a longo prazo, equilibrado, com baixa manutenção e acima de tudo em consonância com princípios ambientais de recuperação da paisagem.

O projeto da criação de alagados construídos tirou partido de nascentes existentes à montante das barragens e das linhas de drenagem natural do terreno que garantiram o fluxo de água necessário para o sistema. Alagados são áreas de solo úmido ou brejoso sujeitas à inundação permanente ou sazonal. O sistema é autosuficiente e estável e sua implantação foi possível devido ao fluxo das águas, 
circulação de nutrientes e fotossíntese. Os elementos constituintes da paisagem são: água, solo e vegetação.

A área de intervenção possui cerca de 120.000 metros quadrados.

\section{SOBRE AS BARRAGENS}

As barragens B-1, B-2 e B-3 consistem em taludes que variam em média de 5 metros de altura, de declividade 1:1.5, comprimento de 110 metros e largura de 4 metros. Em seu interior encontramos uma camada de 6 metros de rejeito de mineração.

No geral, a composição do solo dos reservatórios formados pelas barragens é formada por areia, sílica e argila. O rejeito é argiloso e com areia média de consistência que varia de macia para rígida. Os reservatórios são totalmente preenchidos por rejeito.

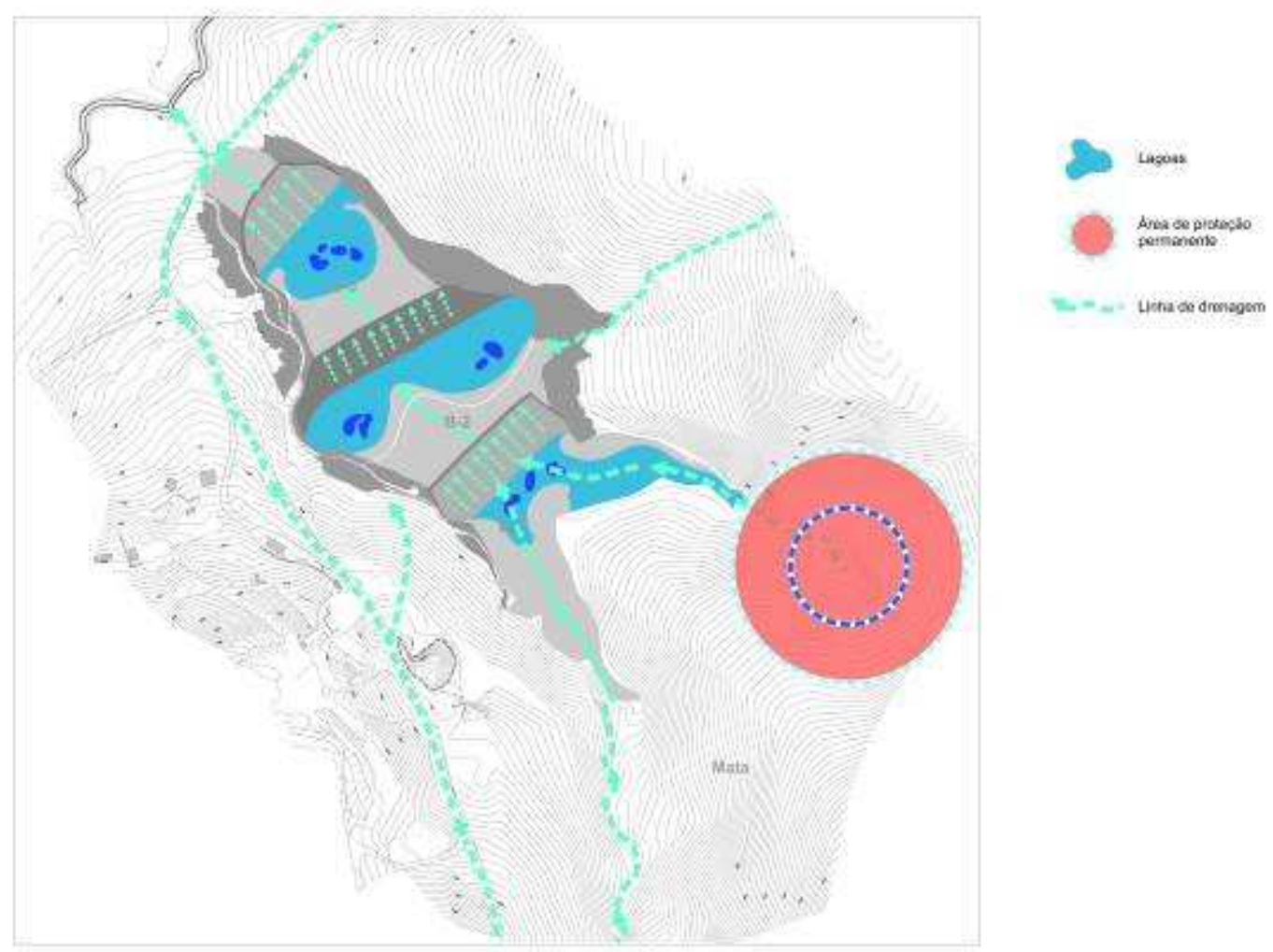

Figura1. Implantação das barragens e indicação do fluxo da água proposto pelo projeto com formação de lagoas e transposição suave dos taludes. (Patrícia Akinaga Arquitetura e Desenho Urbano \& Bureau de Projetos) 


\section{SOBRE O PROJETO PAISAGÍSTICO}

O projeto paisagístico teve como objetivo auxiliar na descaracterização das barragens e reservatórios. Tais elementos foram substituídos pelo sistema de alagados construídos cuja paisagem consiste em taludes suaves, lagoas e plantio de vegetação macrófita.

O projeto foi guiado por princípios geotécnicos, geológicos,hidrológicos e biológicos que foram elaborados por especialistas de cada área.

O processo de construção das idéias foi muito enriquecedor e todos os cálculos cuidadosamente realizados para que houvesse garantia da segurança do sistema após implantação.

O plantio contou com a colaboração de um engenheiro agrônomo que, juntamente com o biólogo e a arquiteta paisagista, definiu espécies adequadas para as diferentes condições de solo em: áreas sujeitas à inundação, áreas permanentemente inundadas, lagoas, taludes com enrocamento, taludes em solo, margens e áreas de reflorestamento. Ver figura 2.

As características da vegetação como diversidade dos portes, texturas e cores enriqueceram a composição paisagística.

As intervenções e a composição resultante levaram em conta as compatibilidades ecológicas das espécies a serem plantadas. $O$ uso de espécies já existentes no local aliado à seleção de espécies segundo diretrizes do biólogo Marcelo Pompeo quanto á sua adaptabilidade ao local foram fundamentais.

As espécies macrófitas já presentes na área de intervenção, devidamente identificadas durante o trabalho de campo realizado pelos biólogos, estão organizadas na tabela abaixo:

Lista de espécies identificadas nas barragens 1, 2 e 3:

\begin{tabular}{lll} 
Família & Espécie & Nome Popular \\
\hline Asteraceae & $\begin{array}{l}\text { Achyrocline satureioides (Lam.) DC. } \\
\text { Baccharis trimera (Lees.) DC } \\
\text { Gymnocoronis sp. DC. }\end{array}$ & $\begin{array}{l}\text { Marcela } \\
\text { Carqueja }\end{array}$ \\
Anacardiaceae & Lithraea sp. Endl. * & \\
& Myracrodruon sp. Allemão * & Aroeira branca \\
Cecropiaceae & & Aroeira preta
\end{tabular}


Cecropia sp. Loefl. *

Embaúba

Cyperaceae

Cyperus haspan $\mathrm{L}$.

Tiririca, Junquinho

Eleocharis minima (L.) Roem. \& Schult.

Rhynchospora holoschoenoides (Rich.) Herter

Droseraceae

Drosera communis A. St.-Hil.

\section{Fabaceae}

Faboideae

Leguminosa

Cajanus cajan (L.) Millsp.

Feijão Gandú

Lamiaceae

Rosmarinus officinalis L.

Alecrim

Lentibulariaceae

Utricularia gibba $L$.

Mururé

\section{Lythraceae}

Cuphea calophylla Cham. \& Schltdl.

\section{Mayacaceae}

Mayaca fluviatilis Aubl.

Melastomataceae

Rhynchanthera limosa DC.

Quaresmeira

Tibouchina sp. *

Quaresmeira

\section{Onagraceae}

Ludwigia octovalvis.

Ludwigia peruviana (L.) H. Hara

Poaceae

Andropogon bicornis L.

Andropogon leucostachyus Kunth

Eragrostis sp.

Imperata brasiliensis Trin

Melinis minutiflora P. Beauv.

Paspalum virgatum $L$.

Pennisetum purpureum Schumach.

Saccharum sp.2

\section{Pterydophyta}

\section{Lycopodium sp. **}

Xyridaceae
Capim-rabo-de-burro

Capim-vassoura

Capim-mimoso

Sapé

Capim-gordura

Capim-de-mula

Capim-napier

Xyris blepharophylla Mart. 
Xyris laxifolia Mart.

$\left(^{\star}\right)$ Plantas que foram coletadas vegetativamente, por isso não foi possível identificar até espécie.

Foram feitas composições de plantas macrófitas na área antes ocupada pelas barragens e outras espécies nativas nas margens adjacentes como forma de promover a integração do projeto com o ecossistema circundante.

Para a cobertura vegetal das margens adjacentes às áreas alagadas foram utilizadas espécies da mata nativa. A grande mancha de vegetação remanescente e as espécies isoladas têm papel importante na integração da área de projeto.

Tais cuidados foram considerados importantes pela equipe a fim de atender às necessidades de recuperação, de reabilitação e porque não dizer, dar qualidade visual às áreas diretamente impactadas.

Além do enriquecimento da biodiversidade e de sua qualidade estética, a vegetação tem a função de diminuir a velocidade do fluxo das águas prevenindo erosões.

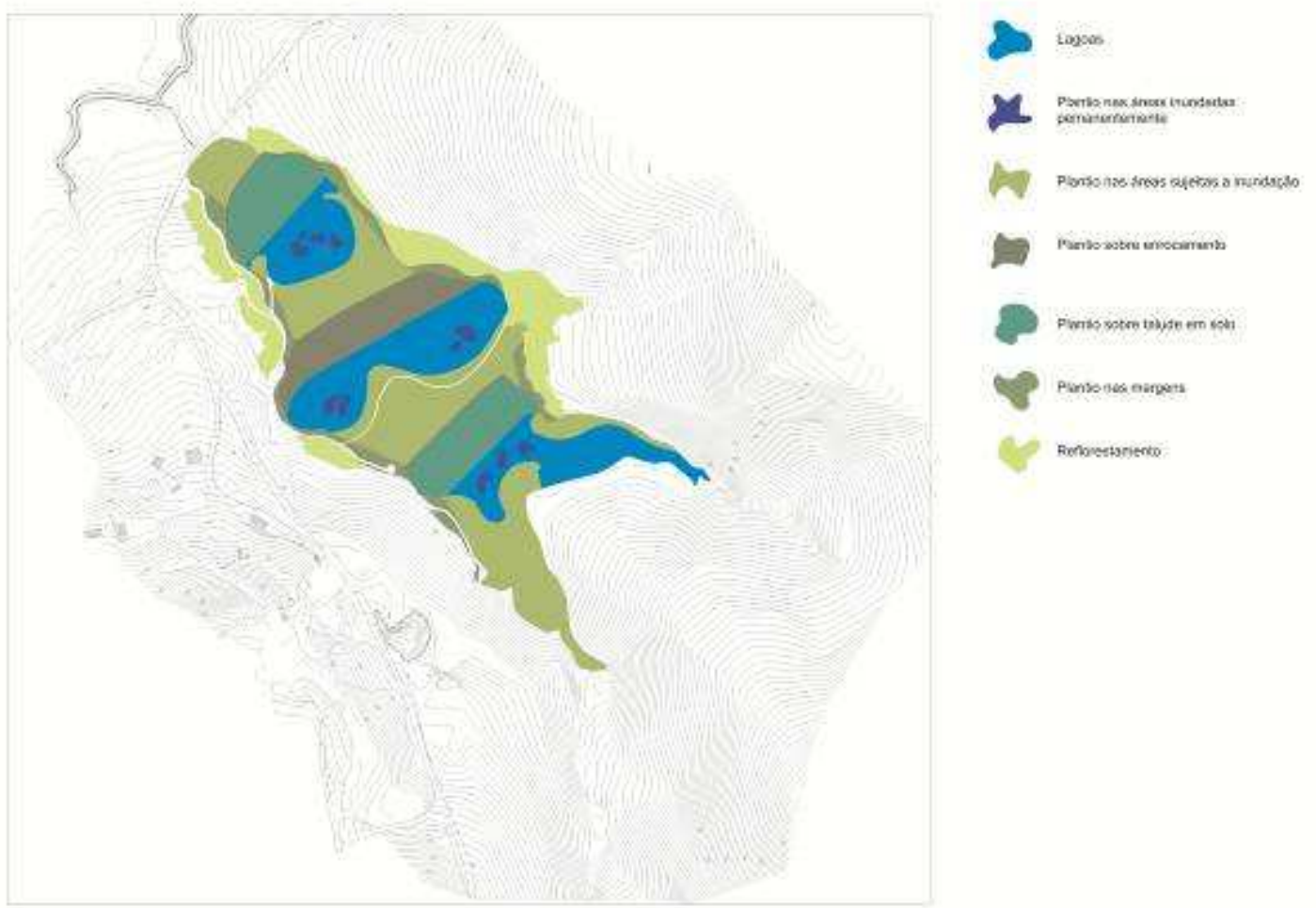

Figura 2. Diagrama ilustrativo do zoneamento de plantio de acordo com as características de solo e fluxo das águas. (Patrícia Akinaga Arquitetura e Desenho Urbano \& Bureau de Projetos) 


\section{- Lagoas, Áreas Permanentemente Inundadas}

As lagoas projetadas no lugar dos reservatórios existentes são também elementos paisagísticos importantes. Além de servir de meio para o desenvolvimento das plantas macrófitas aquáticas propostas, elas "amortecem" e "desaceleram" o fluxo das águas em épocas de cheia. Com o passar do tempo, após a implantação do projeto, o equilíbrio é atingido e uma nova paisagem, revelada.

As lagoas foram criadas próximas aos taludes conforme recomendação do projeto hidráulico. De modo a garantir sua perenidade, a cota de fundo das lagoas está abaixo do lençol freático conforme mostra o corte 1, figura 6 . Foram especificadas para esta área, plantas macrófitas aquáticas:

- Utricularia gibba

- Mayaca fluviatilis

- Eleocharis geniculata

- Nymphaea caerulea

- Nymphoides indica

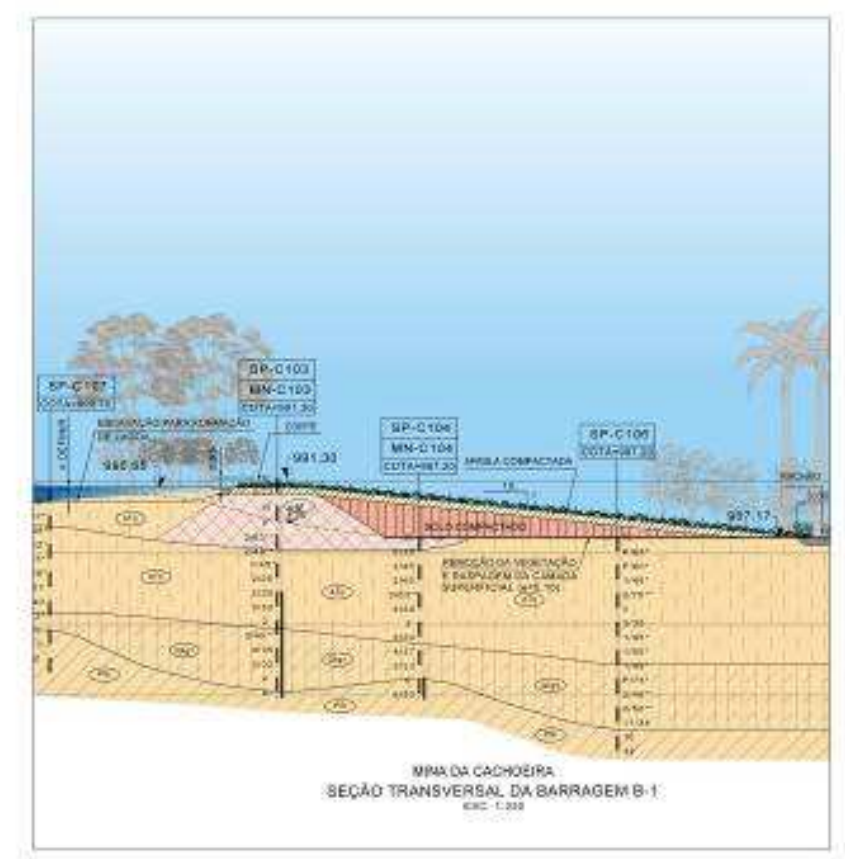

Figura 6. Corte Transversal da Barragem 1, Lagoa e plantio do talude em solo. (Patrícia Akinaga Arquitetura e Desenho Urbano \& Bureau de Projetos) 


\section{- Áreas Sujeitas a Inundações}

Estas áreas sofrem alteração do nível d'água conforme regime de chuvas podendo até secar. As espécies macrófitas adaptáveis a esta condição e selecionadas foram:

- Xyris blepharophylla

- Xyris laxifolia

- Drosera sp.

- Bacopa sp.

- Hedychium coronarium (Lírio-do-Brejo)

- Spermococe suaveolens

- Cuphea calophylla

- Rhynchanthera limosa

- Ludwigia peruviana

- Tibouchina minor

\section{- Talude em Solo ou Enrocamento}

O plantio sobre talude em solo seguiu orientações do engenheiro hidráulico. Foram escolhidas espécies de pequeno porte e herbáceas e seu plantio uniforme não cria obstáculos ao fluxo das águas. O importante para o sistema é a transposição do talude pela água sem a formação de canais que pudessem iniciar o processo erosivo. A escolha mostrou-se correta e a fixação das raízes garantiu a estabilidade.

Foi plantada uma única espécie por talude, com bom enraizamento. No caso do plantio no talude com enrocamento, foram criados "bolsões"de plantio, localizados no vão entre as pedras para o plantio de macrófitas conforme corte 2, figura 7 .

As espécies recomendadas pelo biólogo foram:

- Rhynchospora nervosa

- Bulbostylis capillaris

- Cyperus meyenianus

- Cyperus sesquiflorus 


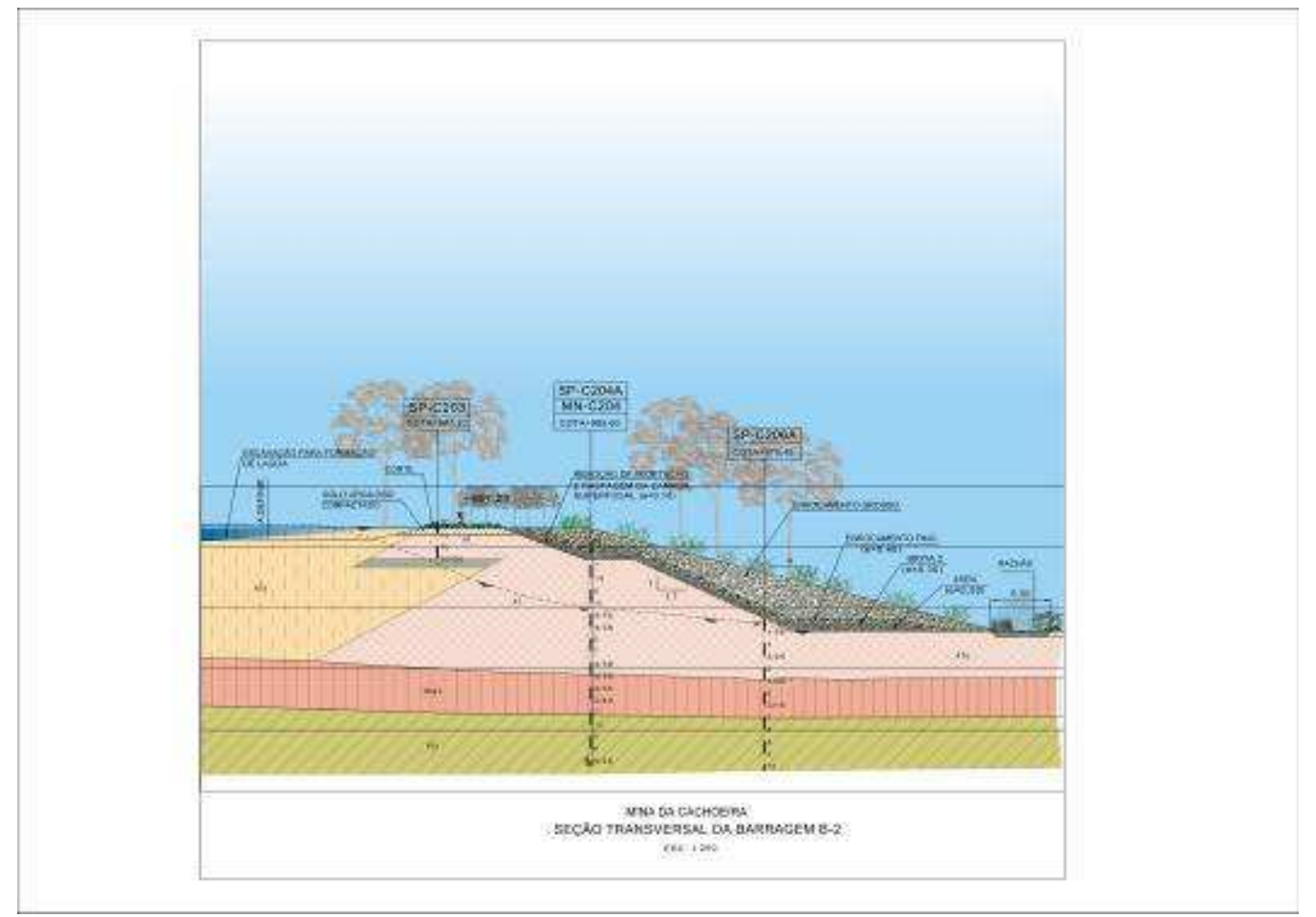

Figura 7.Corte Transversal da Barragem 2, plantio no talude com enrocamento. (Patrícia Akinaga Arquitetura e Desenho Urbano \& Bureau de Projetos)

- Margens

Nas áreas do entorno imediato das barragens foram plantadas espécies nativas para recuperação e reflorestamento. As espécies escolhidas foram:

- Cleome hassleriana

- Ludwigia leptocarpa

- Ipomoea carnea

- Aeschynomene sensitiva

- Payonia cancellata

- Cyperus papyrus

- Rhynchospora corymbosa

- Pluchea sagittalis

- Pycreus decumbens

- Senesio pinnatus

A matriz final de plantio tanto das barragens como das margens dos reservatórios foi gerada em consonância com os pareceres dos biólogos, do engenheiro agrônomo e da arquiteta paisagista (Figura 8). Nela, encontram-se espécies da Mata Atlântica e as macrófitas existentes e selecionadas para o plantio das lagoas e de seu entorno. O resultado foi a descaracterização completa da geometria dos 
reservatórios e o surgimento de uma paisagem integrada ao local e equilibrada. (Figuras 9, 10,11).

\begin{tabular}{|c|c|c|c|c|c|c|c|}
\hline \multirow{2}{*}{ D } & \multirow{2}{*}{ 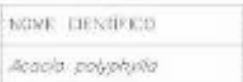 } & \multirow{2}{*}{ 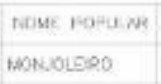 } & \multirow{2}{*}{$\begin{array}{c}\text { POPTE } \\
\text { POI } \\
15: 0\end{array}$} & 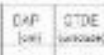 & \multicolumn{3}{|c|}{ cossenomires. } \\
\hline & & & & -47 & \multicolumn{3}{|c|}{ mils it ceromedarento ther.ss in } \\
\hline & 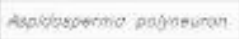 & PETOCOA-POOSA & 20.0 & 40 & \multicolumn{3}{|c|}{ 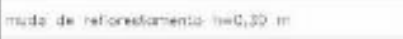 } \\
\hline & 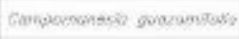 & SPA, NZUHO & 3,0 & 72 & \multicolumn{3}{|c|}{ 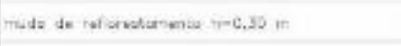 } \\
\hline & 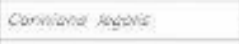 & COUTEL-ROSA & 6,0 & $4 \equiv$ & \multicolumn{3}{|c|}{ 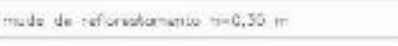 } \\
\hline & Gacropio haterbuos & rorwcen-anusca & 30,0 & $\mathrm{O} \mathrm{g}$ & \multicolumn{3}{|c|}{ 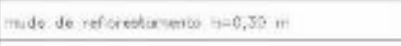 } \\
\hline & Evpanto inmiverots & GEREJERK & 6.0 & 75 & \multicolumn{3}{|c|}{ 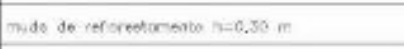 } \\
\hline & Eogeno unitoro & OThaAURRA & 0.0 & 55 & \multicolumn{3}{|c|}{ 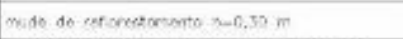 } \\
\hline & Sampary armemangs & GTupnoo & 10,0 & $\begin{array}{l}3,5 \\
45,0 \\
\end{array}$ & \multicolumn{3}{|c|}{ 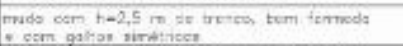 } \\
\hline & meso morapinats. & 1)as & 2,8 & $\begin{array}{l}x, 5 \\
4501 \\
450\end{array}$ & \multicolumn{3}{|c|}{ 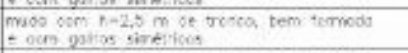 } \\
\hline & moo unguansis & nies & 7,0 & $\begin{array}{ll}3.5 \\
45.9\end{array}$ & \multicolumn{3}{|c|}{ 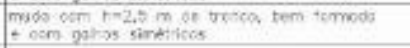 } \\
\hline & 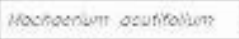 & 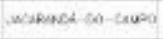 & 9,0 & - & \multicolumn{3}{|c|}{ 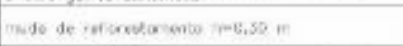 } \\
\hline & Mourtito thoweraso & ULKII & 15,18 & 73 & \multicolumn{3}{|c|}{ 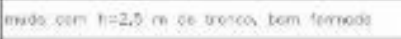 } \\
\hline & 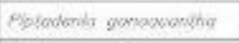 & Phil-jacuet: & 10,0 & $\delta_{2}$ & \multicolumn{3}{|c|}{ 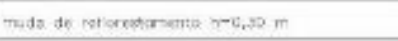 } \\
\hline & Pxistum gugionse & GNABA & 4,0 & 8: & \multicolumn{3}{|c|}{ 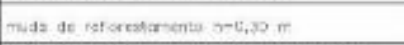 } \\
\hline & Solper Aumbabstions & 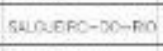 & 12,0 & $\begin{array}{ll}3,5 \\
63,0\end{array}$ & 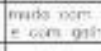 & 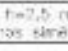 & 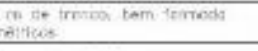 \\
\hline & sorisuabims ponotive & GLAPLRLS & 20,0 & - & mide da 0 & efrementer & 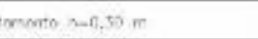 \\
\hline$\frac{1}{4 k}$ & 5papne ateraceo & GLNPाROB & 10,0 & 48 & mide do & er sereeter & meate $n=6,50 \mathrm{~m}$ \\
\hline$y^{2}$ & Sjagner nemantoritions & WETWh & 10,0 & 44 & muts din me & storentox & irenta $n=4,45 \mathrm{~m}$ \\
\hline & 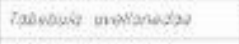 & $1=t-n \cos \theta 0$ & 25,15 & - & mots de co & atornation & anenta $-0,0,32 m$ \\
\hline (b) & 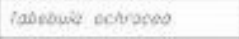 & $1-6-A M+H=1 D$ & 8,6 & - & mats is : & etesents: & ammio $-6,32 \pi$ \\
\hline (a) & 1Rouenshe gronutoss & CWWIESUEKA & 10,6 & 4) & made at is & storets & 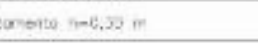 \\
\hline AFEA NL & 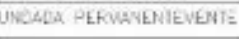 & & & & & & \\
\hline $80 \times 0,0$ & nowe armariso & DGME RORGLAR & $\begin{array}{c}\text { PORTE } \\
\text { int }\end{array}$ & $\sin _{i}$ & $\begin{array}{l}\text { Oroc } \\
\text { sntail }\end{array}$ & 0 & orscrumpors \\
\hline & Unisuranta seos & Nusute & 0.5 & 224.0 & 224 & $\forall / m$ & weifees nevotiel do tontio \\
\hline & Worater chentions & - & 025 & 415.6 & 415 & $\gamma / m^{\prime}$ & 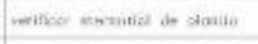 \\
\hline & nymohing cemenuses & DENEEA-AZULL & 040 & 245.9 & 243 & $y / \pi^{*}$ & werilke nessurial th thation \\
\hline 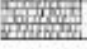 & 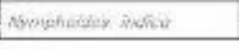 & LROQ C'sOLA & 350 & 479.5 & 479 & $y(n)$ & 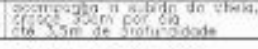 \\
\hline & EY SOLD OU ENROCAMEI & & & & & & \\
\hline SWNED:S & NGNE CIENaIKCO & MONE POPLLAER & $\begin{array}{c}\mathrm{PSOT} \\
(\rightarrow) \\
\end{array}$ & Aigh & Mos & $\stackrel{0}{+\infty}$ & OESERLAOES \\
\hline & Ansactospors navesa & 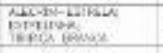 & 0,50 & $5 \pi 0: c$ & 570760 & 0,10 & 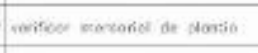 \\
\hline & 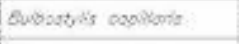 & Nectan of pran & 0.20 & 427,5 & 427150 & 0.10 & verifoer soveriel at santio \\
\hline 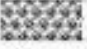 & 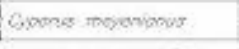 & 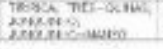 & 020 & $5 / 10,8$ & 571000 & 0,10 . & 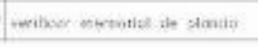 \\
\hline St. & UHelins A Menomgats & & & & & & \\
\hline & 1.NVE CIENIFED & NCME POPULAF & 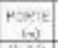 & 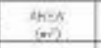 & $\begin{array}{l}\text { Oroes } \\
\text { meluaj } \\
\end{array}$ & 0 & OESERTOAOES \\
\hline & xojy stowhoroetgrfy & - & $\begin{array}{l}0,19 \\
0,12\end{array}$ & 964,5 & 24111 & 0,20 & ientice penoriol de stanso \\
\hline & xone secorotid & - & $\begin{array}{l}9,4 \\
00,11\end{array}$ & 3075,0 & $49 \times 25$ & 0,20 & 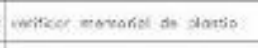 \\
\hline & Onesera in: & - & 0.15 & xoos. 5 & 175050 & 0,20 . & weriticer maveorial do slatio \\
\hline & 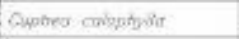 & - & 0.10 & 0372.0 & 157800 & 0.20 & 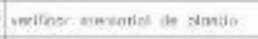 \\
\hline$=1+$ & 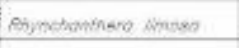 & - & 2,60 & 1500.5 & 30513 & 0,20 & 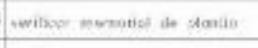 \\
\hline & 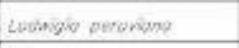 & - & 7,00 & $2 \pi 82,0$ & 69550 & 0,20 & 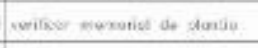 \\
\hline & Whessobina mored & OLAPESMFIFA & 2,20 & 2000,5 & 70213 & 0,20 & 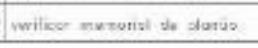 \\
\hline waror: & & & & & & & \\
\hline SINEOD & FUNE LIENAIEO & MOME POPLLAR & $\begin{array}{c}P O Q T E \\
\text { Nog }\end{array}$ & 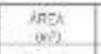 & $\lim _{x \rightarrow \infty}$ & $\begin{array}{ll}0 \\
\text { is }\end{array}$ & ofsiremgats \\
\hline & Crome tossterions? & 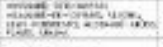 & 1,20 & 435.0 & $5228 \pi$ & 0,30 & 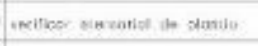 \\
\hline & 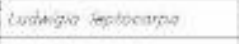 & noRTEno & 0,40 & $134: 5$ & 16028 & 0,30 & 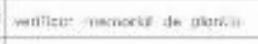 \\
\hline & poomber cames & ALGOSAD ARANO & 2,60 & $81+\sqrt{15}$ & 10968 & 0.30 , & veritoer mavearial ta slantio \\
\hline Antes & Crevons paphos & PRFISP & 2.50 & $5 \times 0,5$ & coste & 0,30 , & wriliker rewaroriat de Alando \\
\hline 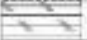 & 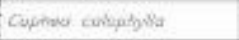 & - & 0,30 & $\Delta 80$, it & $2000 \mathrm{st}$ & 0,211 , & verifixe reverutial de donilo \\
\hline$=$ & 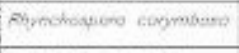 & CAFM-14VALAS & 1,00 & $6: 2,0$ & $7508 \mathrm{t}$ & 0,30 & westice movories of stonsio \\
\hline 24 & Bubastyes espikess & 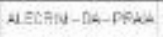 & 0,20 & 78,5 & $7 a 50$ & 0,10 & 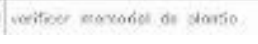 \\
\hline
\end{tabular}


Figura 8. Matriz final de plantio do projeto. (Patrícia Akinaga Arquitetura e Desenho Urbano \& Bureau de Projetos)

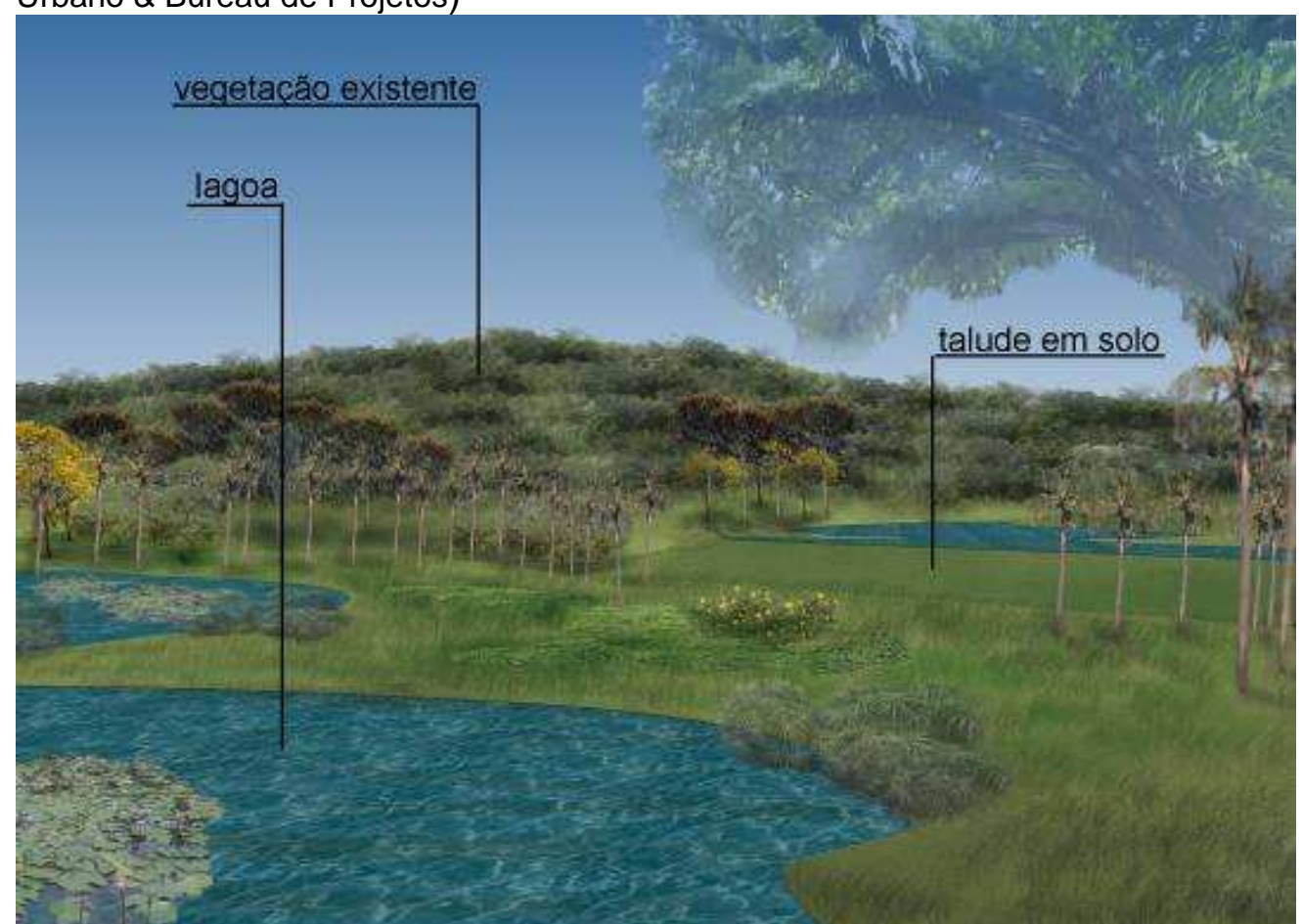

Figura 9. Vista da Barragem B-2 para o talude em solo da Barragem B-1. No plano de fundo, área de reflorestamento com espécies nativas. (Patrícia Akinaga Arquitetura e Desenho Urbano \& Bureau de Projetos)

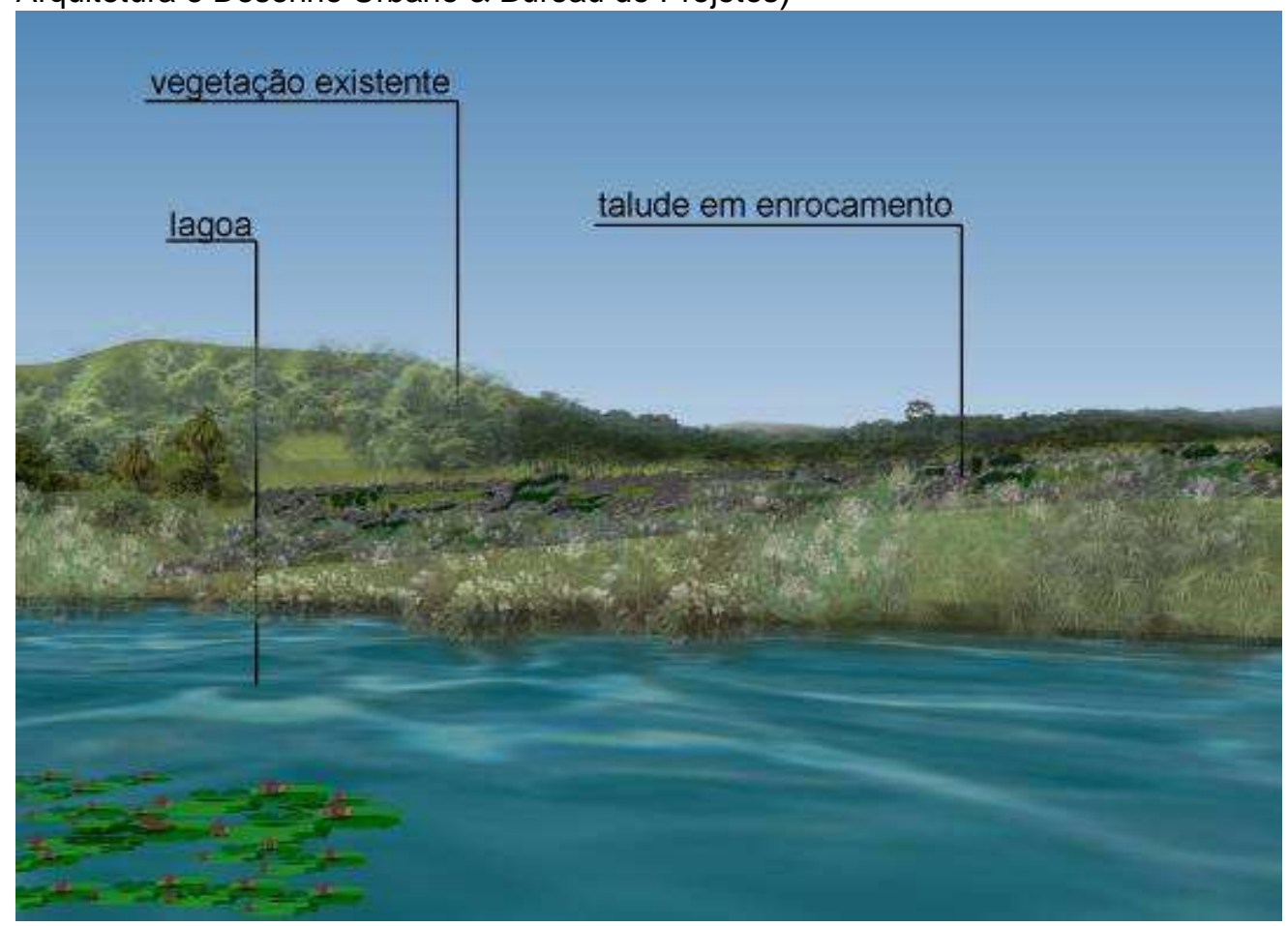


Figura 10. Vista da lagoa da Barragem B-3 para o talude em enrocamento da B-2 com bolsões de plantio preenchidos com vegetação. (Patrícia Akinaga Arquitetura e Desenho Urbano \& Bureau de Projetos)

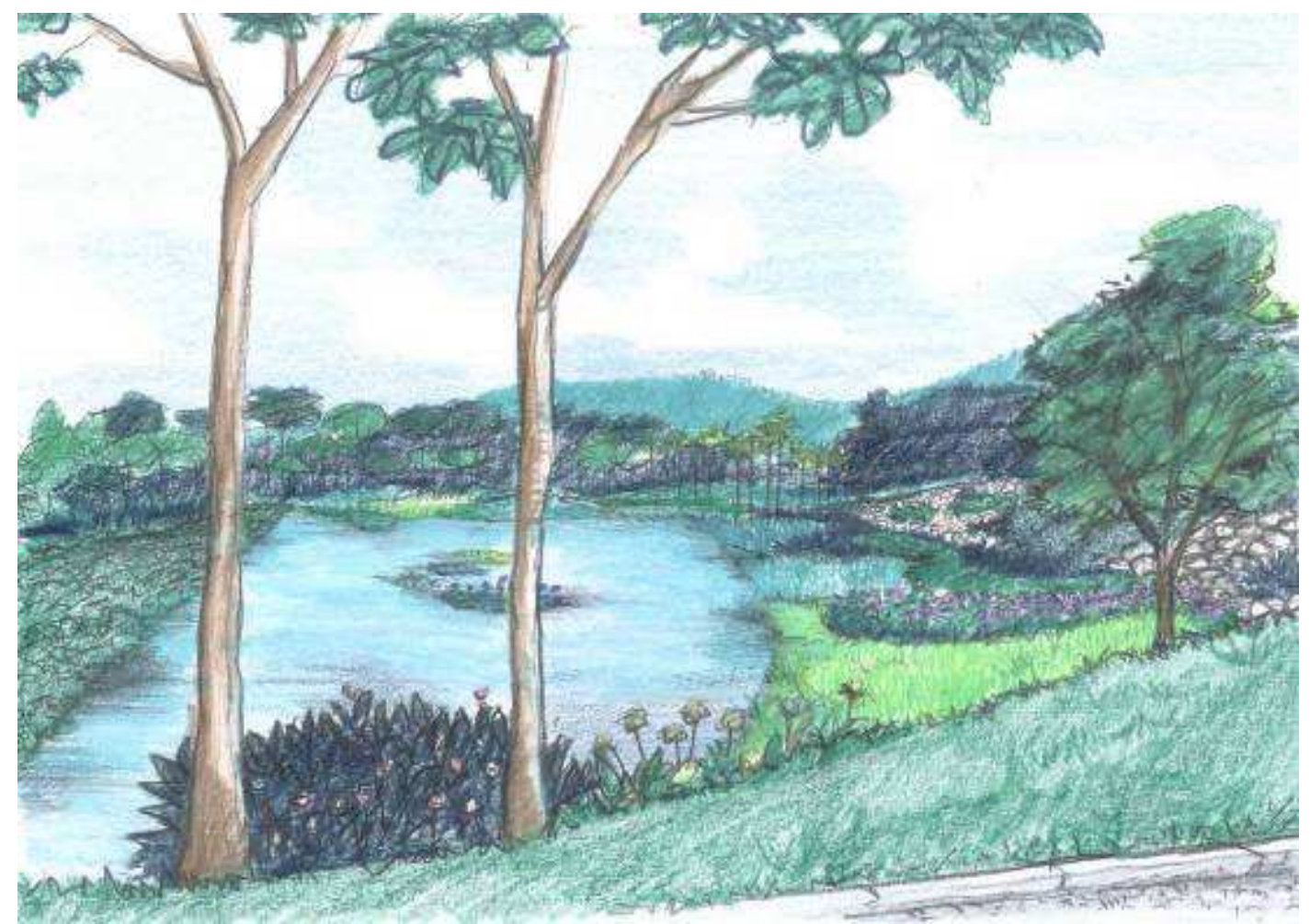

Figura 11. Vista da Barragem B-1 - Margens tratadas com áreas de reflorestamento e lagoa de amortecimento. $O$ talude galgável recebeu plantio uniforme de plantas macrófitas. (Patrícia Akinaga Arquitetura e Desenho Urbano \& Bureau de Projetos)

\section{SOBRE OS ELEMENTOS CONTRUÍDOS}

Muito se discutiu com relação ao uso futuro da área. Concluiu-se que por ser uma experiência inédita, a Mina da Cachoeira transformou-se em projeto piloto para a RDM e outras minas da Vale, sendo base de aprendizado científico durante o processo de implantação e monitoramento e fechada ao acesso público

Para que o monitoramento dos alagados fosse realizado de forma eficiente, foram projetados caminhos palafitados, executados com estrutura em eucalipto autoclavado devidamente certificado e resultante do corte progressivo das áreas das margens reflorestadas com espécies nativas da Mata Atlântica.

Além dos caminhos palafitados nas áreas inundadas e inundáveis, foram criados caminhos de pedrisco para vigilância e monitoramento das wetlands, executados 
conforme detalhado em projeto com camada de $10 \mathrm{~cm}$ de pedrisco fino sobre solo compactado.

O objetivo foi de estabelecer percursos de baixo impacto e de fácil manutenção.

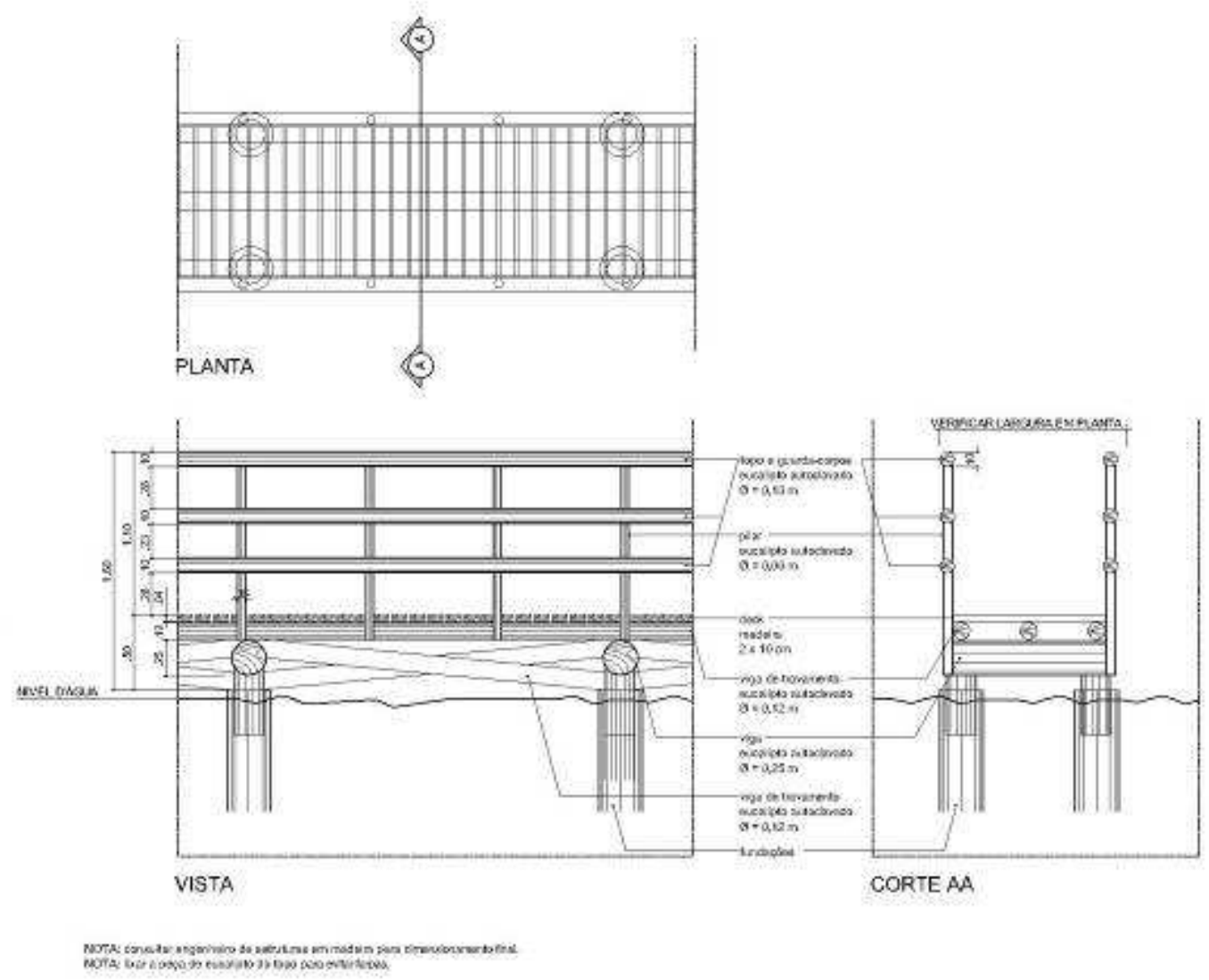

Figura 12. Caminho palafitado dentro dos alagados. (Patrícia Akinaga Arquitetura e Desenho Urbano \& Bureau de Projetos)

\section{ESTUDOS HIDRÁULICOS E GEOTÉCNICOS DE TRANSPOSIÇÃO DOS TALUDES (TRANSBORDAMENTO DAS BARRAGENS)}

\subsection{Condições hidrológicas}

Para o projeto de transbordamento das barragens foi considerada uma média e não o pico de fluxo de um período de retorno de 1.000 anos. A escolha foi em função da relação entre inclinação de taludes e erosão que depende menos do pico e curto prazo e mais da condição média em longo prazo.

4.2 Análise do fluxo sobre a crista e a infraestrutura verde 
As novas estruturas projetadas são construídas a partir da modelagem do terreno sem o auxílio de estruturas de concreto e funcionam como barragens de transbordamento. O comprimento do "vertedouro" corresponde à largura da crista dos reservatórios originais.

Para a análise da vazão sobre os taludes, foi necessário estudar o comportamento do fluxo na crista e a situação da borda das lagoas.

A tabela 1 mostra os resultados dos cálculos hidráulicos para o fluxo na crista sob as condições hidrológicas adotadas.

A lâmina d'água sobre a crista das barragens variou de 12 a $8 \mathrm{~cm}$.

Tabela 1 Análise da vazão sobre a crista:

$\begin{array}{lccccr}\text { Barragem } & \begin{array}{c}\text { Projeto } \\ \text { Vazão - } \\ \text { cheia de } \\ \mathbf{1 . 0 0 0}-\end{array} & \begin{array}{c}\text { Comp } \\ \text { da } \\ \text { crista } \\ (\mathbf{m})\end{array} & \begin{array}{c}\text { Vazão } \\ \text { específica } \\ (\mathbf{m} 3 / \mathbf{s} / \mathbf{m})\end{array} & \begin{array}{c}\text { Lâmina } \\ \text { d'água } \\ \text { (cm) }\end{array} & \begin{array}{r}\text { Velocidade } \\ \text { média(m/s) }\end{array} \\ \text { B-1 } & 3,4 & 98 & 0.035 & 8 & 0.4 \\ \text { B-2 } & 4 & 130 & 0.031 & 7 & 0.4 \\ \text { B-3 } & 4,9 & 80 & 0.061 & 12 & 0.5\end{array}$

\subsection{Análise das condições de erosão e estabilidade}

4.3.1 Suavização dos taludes com solo compactado (Barragens B-1 e B-3) Foi definida com inclinação de $1(\mathrm{~V})$ : $10(\mathrm{H})$ devido à pequena diferença em elevação e ao menor custo sem uso de brita ou material rochoso.

De acordo com as características dos taludes à jusante, o coeficiente de atrito de Manning foi de 0.030 . Entretanto, a presença de vegetação aumenta o atrito de forma significativa (Järvelä, 2002) para 0.050, 0.065 e 0.085

Os três coeficientes de Manning abaixo representam as seguintes condições dos taludes:

$\mu=0.030$ : sem vegetação;

$\mu=0.050$ : fase intermediária (vegetação em desenvolvimento);

$\mu=0.065$ to 0.085 : vegetação plenamente desenvolvida; varia de acordo com a espécie devido espaçamento, densidade das folhas e lâmina d'água sobre as plantas.

A simulação do fluxo foi realizada através do programa HEC-RAS desenvolvido pelo U.S. Bureau of Reclamation, e considerou quatro situações de atrito para cada barragem. 
A análise das velocidades resultantes do fluxo nos taludes concluiu que a erosão pode ser evitada com a colocação de camadas de argila para a média de vazão calculada pela hidrografia projetada associada com a cheia de 1000 anos.

Para o talude da B-3, era numa necessária uma maior suavização, porém, devido à falta de espaço, a inclinação existente foi mantida com as ações de semeadura e plantio iniciados imediatamente após a sua construção.

4.3.2 Suavização do talude com o uso de enrocamento (Barragem B-2) A diferença em elevação entre o rejeito da B-3 e B-2 é de 8,2 metros. A suavização do talude com solo consumiria boa parte da superfície da B-3, cerca de $50 \%$ por isso a solução do enrocamento como adotada. A inclinação de $1(\mathrm{~V}): 4(\mathrm{H})$ foi adotada baseada em experiências em outras barragens na mesma condição.

O fluxo da água entre as rochas foi cuidadosamente estudado, excluindo o risco de deslocamento das mesmas.

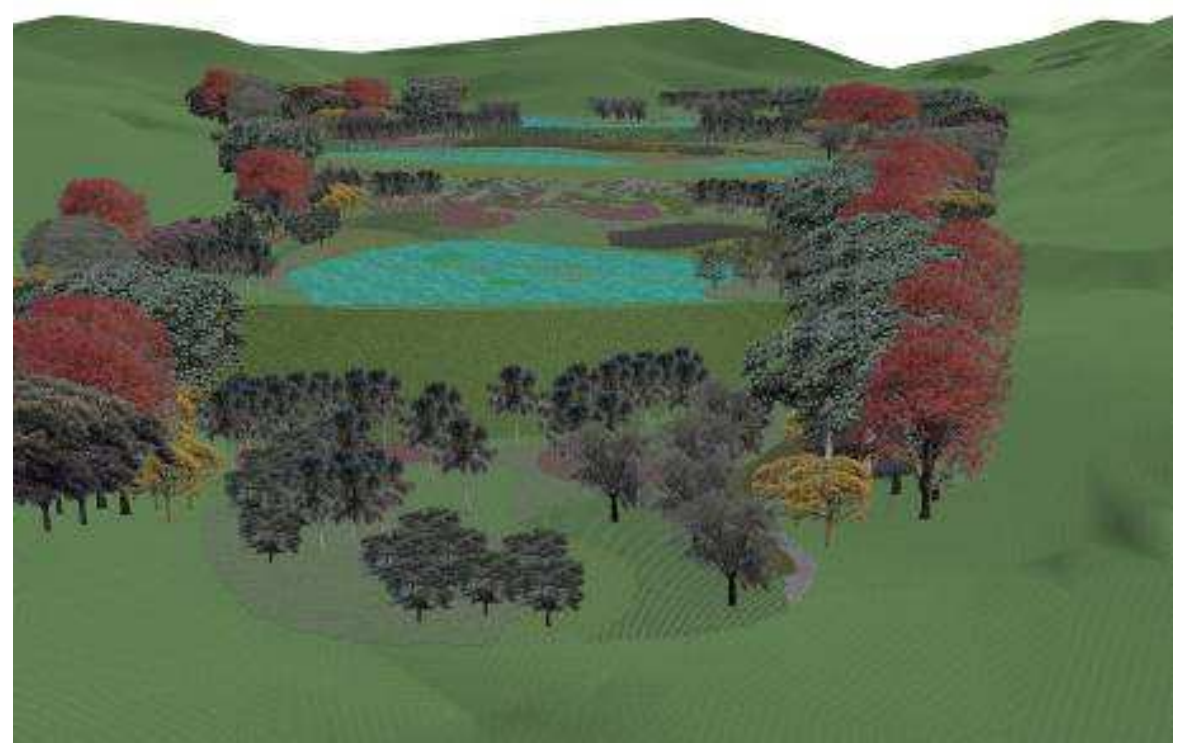

Figura 13A e 13B. Vista geral da paisagem recriada onde antes se encontravam os reservatórios escalonados. (Patrícia Akinaga Arquitetura e Desenho Urbano \& Bureau de Projetos) 


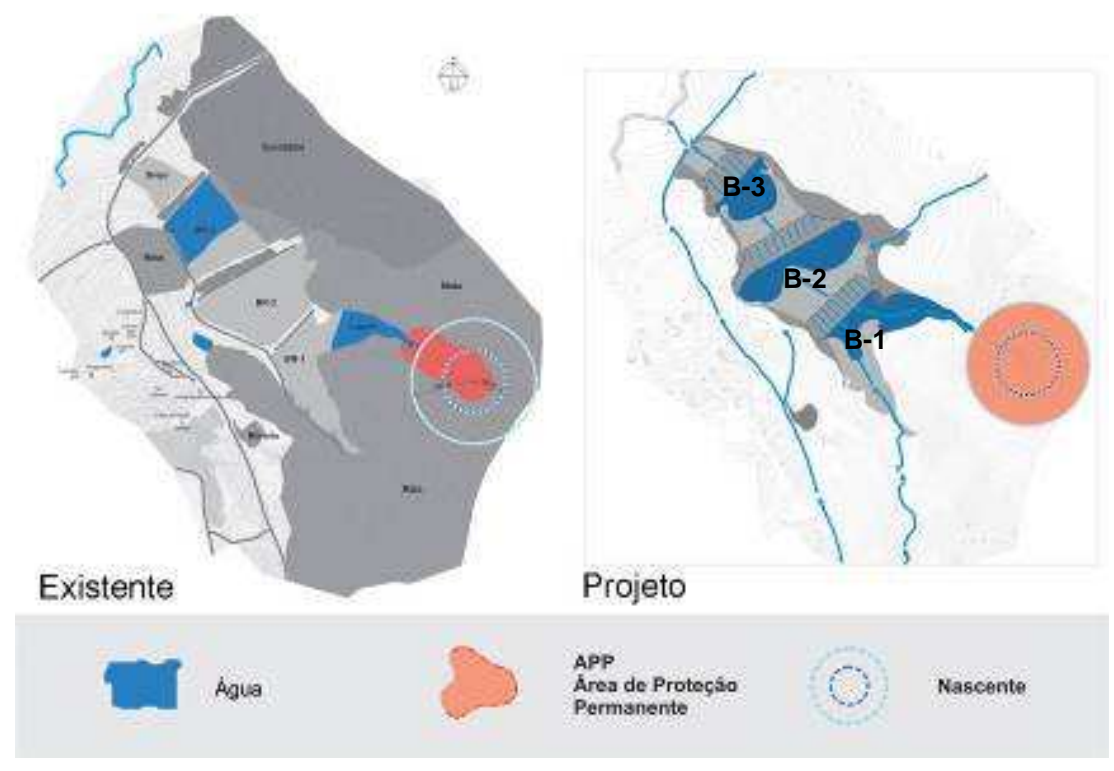

Figura 13B. (Patrícia Akinaga Arquitetura e Desenho Urbano \& Bureau de Projetos)

\section{CONCLUSÃO}

A construção dos alagados construídos terminou em meados de 2009. O plantio está em pleno desenvolvimento e a fase crítica de "pegamento" foi superada com sucesso. O projeto terá seus dados concluídos após, pelo menos, 05 anos de monitoramento. Durante este período, também será observado o processo de sucessão ecológica, pois espontaneamente algumas espécies, melhor adaptadas passarão a predominar na paisagem.

A manutenção principal está na atividade de manejo das espécies nos alagados e em suas margens. O crescimento uniforme nos taludes é fundamental para prevenção de erosão.

Nas áreas de reflorestamento, o corte progressivo do eucaliptal existente resultará na predominância de espécies nativas da Mata Atlântica.

A interação constante da equipe multidisciplinar liderada pela Bureau de Projetos com os técnicos da Vale foi sem dúvida decisiva para a implantação do projeto. Tanto no levantamento de campo como nas análises subseqüentes e soluções adotadas.

A busca por soluções alternativas e mais comprometidas com a questão ambiental por parte da empresa mineradora possibilitou a abertura necessária para o surgimento de novas formas de se pensar estruturas tradicionais como vertedouros e barragens. Os órgãos ambientais locais, após apresentação do projeto, abriram debates sobre o conceito apresentado que não só seguiu a 
legislação como também propôs uma solução mais integrada à própria natureza dando a palavra recuperação um novo sentido.

O objetivo não foi de reconstruir a paisagem que ali um dia existiu, pois após anos de atividade minerária, a dinâmica ecológica se transformou devido à ação antrópica, a alteração da topografia, da fauna e da flora.

A paisagem resultante do projeto apresenta as condições necessárias para a recuperação da biodiversidade local e serve de inspiração para projetistas e cientistas ampliarem suas pesquisas dentro do campo da infraestrutura verde.

\section{REFERÊNCIAS BIBLIOGRÁFICAS}

CARVALHO, J.C., Sales, M.M., Souza, N.M., Silva Melo, M.T. .Processos de erosão no Centro-Oeste do Brasil . Brasília: Ed. Finatec,2006.

JÄRVELÄ, J. Flow resistance of flexible and stiff vegetation: a flume study with natural plants. Journal of Hydrology, 269, pp. 44-54, 2002.

NAMBA, Makoto, Wetlands: a solution to the decommissioning of mining tailings Dams. Artigo aceito para apresentação oral no Congresso Mine Closure, 2010, Vina Del Mar, Chile.

OLIVIER, H. (1967) Through and Overflow Rockfill Dams - New Design

Techniques. Proceedings of the Institute of Civil Engineers, (36) March, pp. 473471.

SALATTI, E. O uso de sistema de alagados construídos para o tratamento de água. Biológico, 65 (1/2, jan/dec), pp. 113-116, 2003.

\section{AGRADECIMENTOS}

Os autores agradecem o apoio fundamental para elaboração do projeto dos professores Luis A. V. de Garcia de Hidrologia e Marcelo L. M. Pompeo da Biologia da Universidade de São Paulo. 